\title{
Produktivnost i kvaliteta ploda tradicionalnih sorti jabuka u intenzivnim sustavima uzgoja
}

\author{
Productivity and fruit quality of traditional apple cultivars within \\ intensive production systems
}

\author{
Bernardica Milinović, P. Vujević, Dunja Halapija Kazija, \\ T. Jelačić, D. Čiček, A. Biško
}

\section{SAŽETAK}

U istraživanju su uspoređene tradicionalne ('Ovčji nos', 'Mašanka' i 'Zlatna zimska parmenka') s otpornim ('Topaz', 'Pinova ${ }^{{ }^{\circledR}}$ ' i 'Querina-Florina') i komercijalnim sortama ('Gala Schnitzer Schniga ${ }^{{ }_{1}}$, 'Golden Delicious Reinders ${ }^{{ }^{\circledR}}$, 'Idared') s ciljem bolje procjene potencijala i kvalitete plodova sorti te za implementaciju ekološki prihvatljivije proizvodnje pojedinih sorti jabuka $\mathrm{u}$ intenzivnom sustavu uzgoja. U usporedbi $\mathrm{s}$ komercijalnim sortama $u$ istraživanju, otporne sorte 'Topaz' i 'Pinova' pokazale su komparativna svojstva s obzirom na produktivnost, dok je sorta 'Querina-Florina' imala značajno manju učinkovitost priroda. Od tradicionalnih sorti izdvaja se sorta 'Ovčji nos' čiji je prirod komparativan s nekim komercijalnim sortama. Kvaliteta ploda svih sorti u istraživanju bila je zadovoljavajuća s obzirom na veličinu ploda te sadržaj topljive suhe tvari.

Ključne riječi: jabuke, tradicionalne sorte, otporne sorte, održivi uzgoj

\begin{abstract}
Traditional cultivars ('Ovčji nos' - 'Schafnase', 'Mašanka' - 'Maschanzker' and 'Zlatna zimska parmenka' - 'Goldparmäne') were compared with resistant ('Topaz', 'Pinova ${ }^{\circledR}$, and 'Querina-Florina') and commercial cultivars ('Gala Schnitzer Schniga ${ }^{\circledR}$, 'Golden Delicious Reinders ${ }^{\circledR}$, and 'Idared') within the system of intensive production aiming to better evaluate production potential, fruit quality and possibilities to implement more ecologically acceptable production practices of certain apple cultivars. In comparison to commercial cultivars, resistant cvs 'Topaz' and 'Pinova' demonstrated relative characteristics with regards to productivity, whilst cv. 'Querina-Florina' had significantly lower yield productivity. Out of traditional cultivars cv. 'Ovčji nos Schafnase' stands out with higher yields relative to certain commercial cultivars. Fruit quality of all cultivars in research was satisfactory when it comes to fruit size and soluble solids content.
\end{abstract}

Key words: apple, traditional cultivars, resistant cultivars, sustainable production 


\section{UVOD}

U ruralnim područjima već dulji niz godina vlada sve veće zanimanje za voćarstvo u sustavu održive poljoprivrede. Pri tome je poseban interes proizvođača i potrošača usmjeren prema našim starim sortama i sortama koje su prikladne za proizvodnju sa smanjenom uporabom kemijskih tretmana (Skendrović Babojelić i sur. 2014). Hrvatska je zemlja s vrlo dugom tradicijom u proizvodnji voća u kojoj autohtone i udomaćene sorte zauzimaju važno mjesto. S obzirom na veliku brojnost, stare sorte predstavljaju bogat izvor genetskog materijala, ali neke sorte imaju i vrlo pozitivne značajke (npr. visoku i redovitu rodnost), što je vrlo važno u uzgoju (Mitre i sur., 2009), a isto tako mogu imati značajan udio u daljnjoj selekciji. Njihova zastupljenost i značenje $u$ prošlosti su bili vrlo veliki, međutim u posljednje vrijeme došlo je do znatnog propadanja starih autohtonih stabala (Jemrić i sur., 2012). Tradicionalne stare sorte voćnih vrsta dragocjeno su bogatstvo i prirodna baština svake zemlje i značajne su iz gospodarskih, agronomskih, bioloških i zdravstvenih razloga. Zavod za voćarstvo Hrvatskog centra za poljoprivredu hranu i selo, od svog osnutka radi na uspostavi kolekcijskog nasada kontinentalnih voćnih vrsta posađenih u pokusnom nasadu u Donjoj Zelini. Kolekcija se sastoji od novih tek introduciranih sorti, sorti otpornih na bolesti i od sorti poznatih gospodarskih svojstava koje su već duže vrijeme prisutne u proizvodnji, a koje su pogodne za uzgoj u intenzivnim sustavima proizvodnje. Posljednjih godina jača svijest o održivoj poljoprivredi, očuvanju bioraznolikosti te raste zanimanje za uzgoj tradicionalnih $\mathrm{i}$ autohtonih sorti, čija je proizvodnja trenutno uglavnom ekstenzivna. U takvim uvjetima uzgoja, bez primjene suvremenih tehnologija, ove sorte uglavnom daju niže prirode.

Posljednjih godina sve se više istražuju mogućnosti uzgoja i upotrebe autohtonih i tradicionalnih sorti voćnih vrsta s ciljem osiguranja visokovrijednih sirovina prehrambenoj industriji, što povoljno utječe na razvoj ruralnog prostora. Uzgoj tradicionalnih i autohtonih sorti povezuje se s manjim troškovima proizvodnje i adaptabilnošću na okolišne čimbenike. Interes malih obiteljskih gospodarstava za uzgojem ovih sorti opada zbog niske isplativosti, tj. plodovi tradicionalnih sorti imaju kraći vijek čuvanja te ne postižu dovoljno visoku cijenu na tržištu. Veliki broj starih sorti odbačen je u proizvodnji i prije introdukcije slaboboujnih podloga, uzgojnih oblika i novih tehnologija uzgoja (Jemrić i sur., 2013). Iako se smatra da ove sorte imaju manji potencijal za dobivanje visokih priroda od komercijalnih sorti, one svojom prilagodbom na lokalne uzgojne uvjete te na bolesti i štetnike osiguravaju stabilnost proizvodnje u ruralnim područjima. 
Istraživanje je provedeno u cilju usporedbe značajki vegetativnog rasta sorti jabuke $u$ istraživnaju, zatim istraživanja razlika u rodnosti usporedbom priroda po stablu i jedinici površine te vanjskih i unutarnjih značajki kvalitete ploda istraživanih sorti radi utvrđivanja prikladnosti uzgoja tradicionalnih sorti $u$ intenzivnim nasadima u usporedbi s najzastupljenijim komercijalnim sortama te sortama otpornim na bolesti.

\section{MATERIJALI I METODE}

Istraživanje je provedeno na odabranim sortama jabuka: tradicionalne ('Ovčji nos', 'Mašanka' i 'Zlatna zimska parmenka'); otporne ('Topaz', 'Pinova ${ }^{\mathbb{B}_{1}}$ i 'QuerinaFlorina') i komercijalne ('Gala Schnitzer Schniga ${ }^{\mathbb{B}}$, 'Golden Delicious Reinders ${ }^{\mathbb{B}}$, 'Idared') posađenim u kolekcijskom nasadu Zavoda za voćarstvo na pokušalištu u Donjoj Zelini. Pokusni voćnjak nalazi se na 150 - $180 \mathrm{~m} \mathrm{n} / \mathrm{v}, 45^{\circ} 55^{\prime} 12^{\prime \prime}$ geografske širine i $16^{\circ} 1442^{\prime \prime}$ geografske dužine. Ovo područje karakterizira prosječna godišnja temperatura od $10,7^{\circ} \mathrm{C}$, i $855,1 \mathrm{~mm}$ ukupnih oborina (DHMZ, 2017.). U voćnjaku je uveden sustav natapanja kap po kap, protugradna mreža te je instalirana stanica za meteorološko praćenje temperature i vlage zraka. Tlo u voćnjaku je okarakterizirano kao pseudoglej. U pokusnom voćnjaku godišnje se provode standardne tehnološke mjere njege i zaštite. Nasad je podignut 2006. godine na podlozi M9, s razmakom sadnje 3,7 x 1,2 m te uzgojnim oblikom vitko vreteno.

Istraživanje je provedeno tijekom 2017. godine u voćnjaku na svekupno 15 stabala, od čega su mjerena 3 stabla u 3 repeticije i to: visina, širina i debljina krošnje (metrom, izražena $\mathrm{u} \mathrm{m}$ ), promjer debla iznad cijepljenog mjesta (pomičnim mjerilom, izraženim u mm). Iz izmjerenih vrijednosti izračunom su dobiveni podaci za površinu poprečnog presjeka debla (TCSA - Trunk cross sectional area) pomoću formule: $\operatorname{TCSA}\left(\mathrm{mm}^{2}\right)=\operatorname{promjer}$ debla $\left.(\mathrm{mm}) / 2\right) 2 \times \pi$, površinu krošnje (PK) pomoću formule: $P K\left(m^{2}\right)=$ (sirina krošnje $(m)+$ debljina krošnje $(m)) / 2$; volumen krošnje $(\mathrm{VK})$ pomoću formule: $V K\left(\mathrm{~m}^{3}\right)=$ površina krošnje $\left(m^{2}\right) \times$ visina krošnje $\left.(m)\right) / 2$. Ukupna masa plodova po stablu utvrđena je vaganjem od svakog pokusnog stabla i izražena u kg. Ukupni prirod po hektaru izračunat je iz podataka prosječne amse po stablu i broja stabala na hektar površine. Pomološka mjerenja sorti $u$ istraživanju obuhvatila su mjerenja na 30 plodova prosječne mase ploda (vaganjem na vazi Karren, Mettler Toledo, izraženim u g), visine i opsega ploda (mjerenjem pomičnom mjerkom, Comecta, Italija, izražene u mm). Tvrdoća ploda destruktivno utvrđena je Magness Taylor testom pomoću penetrometra FT327, Italija, izraženim u $\mathrm{kg} / \mathrm{cm}^{2}$ ). Topljiva suha tvar ploda utvrđena je direktnim očitanjem soka na refraktometru PAL Atago, izražena $\mathrm{u}{ }^{\circ}$ Brixa. Dobiveni rezultati statistički su obrađeni statističkim programom Statistica 10.0 (StatSoft, Inc., USA). 


\section{REZULTATI I RASPRAVA}

Sorte $u$ pokusu su se značajno razlikovale s obzirom na površinu poprečnog presjeka debla. Komercijalne i tradicionalne sorte u prosjeku su imale manju površinu poprečnog presjeka debla od otpornih osim sorte 'Pinova ${ }^{{ }^{B}}$ (Tablica 1.). Najveću površinu poprečnog presjeka debla imala je sorta 'Querina Florina' $\left(168,80 \mathrm{~mm}^{2}\right)$ te potom 'Topaz' $\left(140,37 \mathrm{~mm}^{2}\right)$ i ove razlike su statistički značajne. Razlike između ostalih sorti u istraživnaju nisu značajne. Rezultati ovih istraživanja su u suglasju s istraživanjem koje su proveli Czynczyk i sur. (2005) na sortama 'Pinova ${ }^{\mathbb{B}_{1}}$ i 'Topaz' u Poljskoj. Veličina i oblik krošnje odražavaju vitalnost stabla i imaju središnju ulogu u produktivnosti stabla. Površina i volumen krošnje u pozitivnoj su vezi s poprečnim presjekom debla. Stoga su najveća površina i volumen krošnje utvrđeni kod sorte 'QuerinaFlorina' u odnosu na ostale sorte u istraživanju i ove razlike su statistički značajne. Odstupanje od pozitivne veze između površine poprečnog presjeka debla i površine krošnje uočeno je kod sorte 'Mašanka' koja je imala manju površinu poprečnog presjeka debla a njezina površina krošnje slijedi odmah nakon krošnje 'Querine-Florine'. Značajke vegetativnog rasta komercijalnih i tradicionalnih sorti u istraživanju nisu se značajno razlikovale.

Tablica 1. Prosječne vrijednosti površine poprečnog presjeka debla (Trans cross section area - TCSA), površine i volumena krošnje istraživanih sorti cijepljenih na podlogu M9 u 10. godini istraživanja

Table 1 Mean values of trans cross section area (TCSA), canopy area and canopy volume of cultivars in research grafted on $M 9$ rootstcok in $10^{\text {th }}$ year after planting

\begin{tabular}{|r|c|c|c|}
\hline \multicolumn{1}{c|}{$\begin{array}{c}\text { Sorta } \\
\text { Cultivar }\end{array}$} & $\begin{array}{c}\text { Površina poprečnog presjeka } \\
\text { debla / Trans cross section area } \\
\left(\mathrm{mm}^{2}\right)\end{array}$ & $\begin{array}{c}\text { Površina krošnje } \\
\text { Canopy area } \\
\left(\mathrm{m}^{2}\right)\end{array}$ & $\begin{array}{c}\text { Volumen krošnje } \\
\text { Canopy volume } \\
\left(\mathrm{m}^{3}\right)\end{array}$ \\
\hline Golden Delicious Reinders & $62,24 \mathrm{c}$ & $1,41 \mathrm{bc}$ & $2,13 \mathrm{~b}$ \\
\hline Gala Schnitzer Schniga & $67,04 \mathrm{c}$ & $1,37 \mathrm{c}$ & $2,19 \mathrm{~b}$ \\
\hline Idared & $73,51 \mathrm{c}$ & $1,43 \mathrm{bc}$ & $2,17 \mathrm{~b}$ \\
\hline Pinova & $69,02 \mathrm{c}$ & $1,33 \mathrm{c}$ & $1,98 \mathrm{~b}$ \\
\hline Topaz & $140,37 \mathrm{ab}$ & $1,53 \mathrm{bc}$ & $2,26 \mathrm{~b}$ \\
\hline Querina Florina & $168,80 \mathrm{a}$ & $2,08 \mathrm{a}$ & $3,47 \mathrm{a}$ \\
\hline Mašanka & $72,42 \mathrm{c}$ & $1,66 \mathrm{~b}$ & $2,29 \mathrm{~b}$ \\
\hline Ovčji nos & $74,77 \mathrm{c}$ & $1,53 \mathrm{bc}$ & $2,07 \mathrm{~b}$ \\
\hline Zlatna zimska parmenka & $121,80 \mathrm{c}$ & $1,41 \mathrm{bc}$ & $2,10 \mathrm{~b}$ \\
\hline
\end{tabular}

Napomena: vrijednosti označene različitim slovom značajno se razlikuju prema Fisher LSD testu uz P $\leq 0.05$ 
U godini istraživanja (proljeće 2017.) pokusna stabla pretrpjela su štete od mraza što je utjecalo na produktivnost i kvalitetu plodova istraživnaih sorti. Prirod po stablu (Tablica 2.) statistički je značajno varirao po sortama i bio je najveći kod sorte 'Golden Delicious Reinders ${ }^{\circledR 1}(22,63 \mathrm{~kg} / \mathrm{stablo})$ a najmanji kod 'Zlatne zimske parmenke' $(4,73)$. Očekivano, u prosjeku su komercijalne sorte imale najveći prirod a slijede otporne i tradicionalne izuzevši sorti 'Gala Schnitzer Schniga ${ }^{\mathbb{Q}_{1}}$ koja je imala značajno manji prirod po stablu od sorti 'Golden Delicious Reinders ${ }^{\mathbb{B}_{1}}$, 'Idared' te 'Topaz' i 'Pinova ${ }^{\mathbb{B}_{1}}$. Od otpornih sorti izdvaja se sorta 'Querina-Florina' kod koje je utvrđen značajno manji prirod od ostalih otpornih sorti. Kod tradicionalnih sorti izdvojila se sorta 'Ovčji nos' čiji je prirod po stablu značajno veći od sorti 'Mašanka' i 'Zlatna zimska parmenka' te nešto manji od sorte 'Gala Schnitzer Schniga ${ }^{\circledR}$. S obzirom na prirod po hektaru (Tablica 2.) vidljivo je da su sorte 'Idared' i 'Golden Delicious Reinders ${ }^{\mathbb{B}_{1}}$ bile manje pogođene mrazom od sorte 'Gala Schnitzer Schniga ${ }^{\mathbb{B}_{1}}$. Od otpornih, sorta 'Querina-Florina' nije ostvarila značajan prirod, dok se od tradicionalnih sorti izdvaja 'Ovčji nos' s približno visokim prirodom kao i pojedine komercijalne sorte.

Tablica 2. Prosječne vrijednosti priroda po stablu i priroda po jedinici površine za sorte u istraživanju cijepljene na podlogu M9 u 10. godini istraživanja

Table 2 Mean values of yield per tree and per hectar for cultivars in research grafted on $\mathrm{M9}$ rootstcok in $10^{\text {th }}$ year after planting

\begin{tabular}{|r|l|l|}
\hline \multicolumn{1}{c|}{$\begin{array}{c}\text { Sorta } \\
\text { Cultivar }\end{array}$} & $\begin{array}{c}\text { Prirod/stablo } \\
\text { Yield/tree }(\mathrm{kg})\end{array}$ & $\begin{array}{c}\text { Prirod/ha } \\
\text { Yield/ha (t) }\end{array}$ \\
\hline Golden Delicious Reinders & $22,63 \mathrm{a}$ & $50,97 \mathrm{a}$ \\
\hline Gala Schnitzer Schniga & $11,80 \mathrm{bcd}$ & $26,58 \mathrm{bcd}$ \\
\hline Idared & $17,87 \mathrm{ab}$ & $40,24 \mathrm{ab}$ \\
\hline Pinova & $17,13 \mathrm{abc}$ & $38,58 \mathrm{abc}$ \\
\hline Topaz & $15,90 \mathrm{bc}$ & $35,81 \mathrm{bc}$ \\
\hline Querina Florina & $6,87 \mathrm{de}$ & $15,46 \mathrm{de}$ \\
\hline Mašanka & $6,30 \mathrm{de}$ & $14,19 \mathrm{de}$ \\
\hline Ovčji nos & $11,20 \mathrm{cde}$ & $25,22 \mathrm{cde}$ \\
\hline Zlatna zimska parmenka & $4,73 \mathrm{e}$ & $10,66 \mathrm{e}$ \\
\hline
\end{tabular}

Napomena: vrijednosti označene različitim slovom značajno se razlikuju prema Fisher LSD testu $\mathrm{uz} P \leq 0.05$

Rezultati ovog istraživanja za sve tradicionale sorte osim za 'Ovčji nos' u skladu su s istraživanjem koje su proveli Wurm i sur. (2015) u Austriji na 16 tradicionalnih sorti uzgajanih u intenzivnim sustavima uzgoja, od kojih su sorte 
'Mašanka' i 'Zlatna zimska parmenka' imale prosječne prirode po stablu u odnosu na ostale sorte u istraživanju. Odnos površine poprečnog presjeka debla kao značajke koja neposredno opisuje snagu rasta stabla i priroda po stablu koristi se u procjeni učinkovitosti priroda pojedine sorte. Uspoređujući odnos prosječnog priroda po stablu i površine poprečnog presjeka debla (Grafikon 1.), vidljivo je da su sve komercijalne sorte imale učinkovite prirode. Od otpornih izdvaja se sorta 'Pinova ${ }^{{ }_{1}}$ čija je učinkovitost priroda komparativna sorti 'Idared'. Sorte 'Topaz', a posebice sorta 'Querina-Florina' nisu dale učinkovite prirode. Od tradicionalnih sorti pozitivan omjer priroda po stablu s obzirom na površinu poprečnog presjeka debla vidljiv je kod sorte 'Ovčji nos', dok sorte 'Mašanka' i 'Zlatna zimska parmenka' nisu dale učinkovite prirode.

Grafikon 1. Odnos prosječnog priroda po stablu (kg) i površine poprečnog presjeka debla $\left(\mathrm{cm}^{2}\right)$ sorti u istraživanju cijepljenih na podlozi M9 u 10. godini istraživanja

Graph 1 Average yield per tree $(\mathrm{kg})$ and trans cross section area $\left(\mathrm{cm}^{2}\right)$ ratio of cultivarts in research grafted on $\mathrm{M9}$ rootstock in $10^{\text {th }}$ year after planting

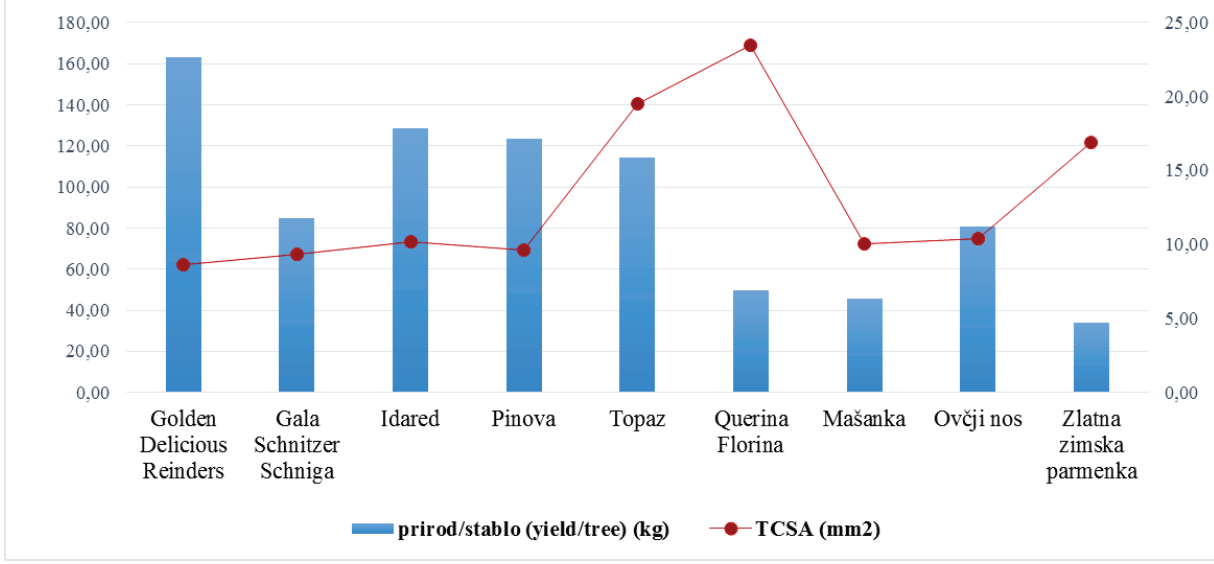

- TCSA - trans cross section area - poprečni presjek debla

Vanjski parametri kvalitete ploda (veličina, boja i oblik) te unutarnja kvaliteta ploda (topljiva suha tvar, okus i tekstura) glavni su čimbenici koji utječu na prihvaćenost ploda jabuke od strane potrošača (Janick i sur., 1996; Brown i Maloney, 2003). Veličina ploda prvenstveno je sortno svojstvo, a djelomice je rezultat tehnologije uzgoja i agro-ekoloških uvjeta. U ovom istraživanju, tradicionalne sorte su imale u prosjeku najmanju masu ploda, a 
slijede komercijalne te otporne sorte (Tablica 3.). Najveću masu ploda imala je sorta 'Topaz' (189,60 g). Slijede sorte 'Idared' (188,23 g) te 'Querina-Florina' $(185,04 \mathrm{~g})$ i te razlike nisu statistički značajne. Sorte su se razlikovale s obzirom na visinu ploda, gdje su tradicionalne sorte također imale najmanju visinu a slijede otporne i komercijalne. Sorta 'Ovčji nos' je imala najmanji opseg ploda a 'Topaz' najveći i ove razlike su statistički značajne (Tablica 3.). Razlike u masi ploda između sorti 'Topaz', 'Idared' i 'Querina -Florina' nisu statistički značajne. Sve tradicionalne sorte bile su manjeg opsega ploda i te razlike su statistički značajne. Ovi rezultati su u suglasju s rezultatima Keppela i sur. (2001) koji su provedeni na tradicionalnim u usporedbi s komercijalnim sortama jabuke u uvjetima Štajerske, Austrija, gdje je sorta 'Ovčji nos' imala $50 \%$, a 'Zlatna zimska parmenka' $25 \%$ manji plod od sorti 'Idared' i 'Golden Delicious' te 'Gala'.

Tablica 3. Prosječne vrijednosti fizikalno-kemijskih svojstava plodova istraživanih sorti cijepljenih na podlogu M9 u 10. godini istraživanja

Table 3 Mean values of physio-chemical characteristics of fruit of cultivars in research grafted on $\mathrm{M9}$ rootstock in $10^{\text {th }}$ year after planting

\begin{tabular}{|r|c|c|c|c|c|}
\hline \multicolumn{1}{|c|}{$\begin{array}{c}\text { Sorta } \\
\text { Cultivar }\end{array}$} & $\begin{array}{c}\text { Masa } \\
\text { ploda } \\
\text { Fruit } \\
\text { weight } \\
(\mathrm{g})\end{array}$ & $\begin{array}{c}\text { Visina } \\
\text { ploda } \\
\text { Fruit } \\
\text { height } \\
(\mathrm{mm})\end{array}$ & $\begin{array}{c}\text { Obujam } \\
\text { ploda } \\
\text { Fruit } \\
\text { circumf. } \\
(\mathrm{mm})\end{array}$ & $\begin{array}{c}\text { Tvrdoća } \\
\text { ploda } \\
\text { Fruit } \\
\text { firmnes } \\
\left(\mathrm{kg} / \mathrm{cm}^{2}\right)\end{array}$ & $\begin{array}{c}\text { Topljiva suha } \\
\text { tvar total } \\
\text { Soluble solids } \\
\left({ }^{\circ} \text { Brix }\right)\end{array}$ \\
\hline Golden Delicious Reinders & $174,77 \mathrm{~b}$ & $68,61 \mathrm{a}$ & $74,80 \mathrm{~b}$ & $6,34 \mathrm{~d}$ & $13,63 \mathrm{e}$ \\
\hline Gala Schnitzer Schniga & $157,06 \mathrm{c}$ & $67,42 \mathrm{a}$ & $70,73 \mathrm{c}$ & $6,11 \mathrm{de}$ & $13,11 \mathrm{e}$ \\
\hline Idared & $188,23 \mathrm{ab}$ & $64,07 \mathrm{ac}$ & $79,40 \mathrm{a}$ & $6,03 \mathrm{de}$ & $13,30 \mathrm{e}$ \\
\hline Pinova & $154,17 \mathrm{c}$ & $62,03 \mathrm{bc}$ & $73,30 \mathrm{~b}$ & $5,82 \mathrm{e}$ & $13,56 \mathrm{e}$ \\
\hline Topaz & $189,60 \mathrm{a}$ & $60,81 \mathrm{~b}$ & $79,60 \mathrm{a}$ & $7,07 \mathrm{c}$ & $15,96 \mathrm{c}$ \\
\hline Querina Florina & $185,04 \mathrm{ab}$ & $66,71 \mathrm{ab}$ & $77,60 \mathrm{a}$ & $7,30 \mathrm{bc}$ & $16,82 \mathrm{~b}$ \\
\hline Mašanka & $105,11 \mathrm{e}$ & $51,95 \mathrm{f}$ & $64,87 \mathrm{e}$ & $8,80 \mathrm{a}$ & $17,58 \mathrm{a}$ \\
\hline Ovčji nos & $101,18 \mathrm{e}$ & $60,81 \mathrm{~b}$ & $59,77 \mathrm{f}$ & $8,59 \mathrm{a}$ & $14,92 \mathrm{~d}$ \\
\hline Zlatna zimska parmenka & $125,96 \mathrm{~d}$ & $56,72 \mathrm{e}$ & $67,97 \mathrm{~d}$ & $7,70 \mathrm{~b}$ & $15,62 \mathrm{c}$ \\
\hline
\end{tabular}

Napomena: vrijednosti označene različitim slovom značajno se razlikuju prema Fisher LSD testu uz $\mathrm{P} \leq 0.05$

Najmanju tvrdoću ploda imala je sorta 'Pinova ${ }^{\circledR}$, a najveću 'Mašanka' i ove razlike su statistički značajne (Tablica 3.). U prosjeku su sve tradicionalne sorte imale veću tvrdoću a potom otporne sorte 'Topaz' i 'Querina-Florina'. Sve komercijalne sorte su imale tvrdoću manju od $6,50 \mathrm{~kg} / \mathrm{cm}^{2}$. Ovi rezultati su u skladu sa standardima za sorte $u$ istraživanju.

Sadržaj topljive suhe tvari kretao se od $13,11{ }^{\circ}$ Brixa ('Gala Schnitzer Schniga ${ }^{\circledR}$ ) do $17,58{ }^{\circ}$ Brixa ('Mašanka') (Tablica 3.). Razlike u sadržaju topljive suhe tvari kod komercijalnih sorti i sorte 'Pinova ${ }^{\circledR 1}$ nisu bile statistički značajne i bile su manje od $13,70{ }^{\circ}$ Brixa. Sorta 'Ovčji nos' imala je jedina srednju 
vrijednost topljive suhe tvari od svih sorti u istraživanju, dok su ostale tradicionalne i otporne imale sadržaj topljive suhe tvari veći od $15,50{ }^{\circ}$ Brixa (Tablica 3.). Za sorte 'Topaz' i 'Pinova ${ }^{\circledR}$ u ovom istraživanju su rezultati viši, dok su za komercijalne sorte 'Gala' i 'Golden Delicious' značajno niži u usporedbi s istraživanjem koje su proveli Soska i Tomala (2006) u Poljskoj $\left(14,9 ; 16,00^{\circ}\right.$ Brixa). Ovo istraživanje u suglasju je s istraživanju Keppela i sur. (2001) za tradicionalne sorte 'Ovčji nos' i 'Zlatna zimska parmenka' koje su imale u prosjeku $25 \%$ i $50 \%$ viši sadržaj topljive suhe tvari od komercijalnih sorti 'Gala', 'Idared' i 'Golden Delicious'.

\section{ZAKLJUČAK}

U usporedbi s komercijalnim sortama u istraživanju, otporne sorte 'Topaz' i 'Pinova ${ }^{\mathbb{B}_{1}}$ pokazale su komparativna svojstva s obzirom na produktivnost, dok je sorta 'Querina-Florina' imala značajno manji prirod po stablu s obzirom na bujnost stabla. Od tradicionalnih sorti može se izdvojiti sorta 'Ovčji nos' čiji je prirod komparativan čak i s nekim komercijlanim sortama ('Gala Schnitzer Schniga $\left.{ }^{{ }^{\circledR}}\right)$. Kvaliteta ploda svih sorti u istraživanju bila je zadovoljavajuća $s$ obzirom na veličinu ploda i osnovne fiziklano-kemijske parametre. S obzirom na pojavu mraza tijekom vegetacije koja je utjecala na oštećenost plodova kod nekih sorti, potrebno je nastaviti s istraživanjem u narednim godinama i utvrditi produktivnost otpornih $\mathrm{i}$ tradicionalnih sorti te sklonost alternaciji $\mathrm{u}$ promatranim agro-ekološkim uvjetima zapadne Hrvatske.

Napomena: Ovo istraživanje financirano je kroz projekt ,, Nove tehnologije uzgoja starih sorti jabuka u održivom sustavu proizvodnje“ Vijeća za istraživanje u poljoprivredi.

\section{LITERATURA}

BROWN S.K., MALONEY K.E. (2003.): Genetic improvement of apple: breeding, markers, mapping and biotechnology. In: Ferree D., Warrington I. (eds) Apples: botany, production and users. CAB International, Wallingford, UK; 31-59.

CZYNCZYK A., BIELICKI P., MIKA A., KRAWIEC A. (2005.): Growth and yielding in six scab-resistant apple cultivars grafted on three dwarfing rootstocks in integrated fruit production. Journal of Fruit and Ornamental Plant Research, Vol. 13: 19-23. 
DRŽAVNI HIDROMETEOROLOŠKI ZAVOD - DHMZ; 2017.: Praćenje klime, http://klima.hr/klima.php?id=k2

JANICK J., CUMMINS J.N., BROWN S.K, HEMMAT M. (1996.): Apples. In: Janick J., Moore J. (eds) Fruit Breeding, Vol I: Tree and Tropical Fruits. John Wiley 6 Sons, New Yor, 1-7.

JEMRIĆ, T., FRUK, G., ČIČEK, D., SKENDROVIĆ BABOJELIĆ, M., ŠINDRAK, Z. (2012.): Preliminary results of fruit quality of eight Croatian local apple cultivars. Agriculturae Conspectus Scientificus. 77 (4): 223-226.

JEMRIĆ, T., SKENDROVIĆ BABOJELIĆ, M., FRUK, G., ŠINDRAK Z. (2013.): Fruit quality of nine old apple cultivars. Notulae Botanicae. Horti Agrobotanici Cluj-Napoca 41 (2): 504-509.

KEPPEL, H., HOFER, M., TAUSZ, M., GRILL D. (2001.): Eine Genbank fiir Kernobstsorten in der Steiermark und eine Analyse ihrer Apfelsorten (Malus domestica $\times$ Rosaceae-Maloideae). Mitt. natunviss. Ver. Steiermark, 131: 129-139

MITRE, I., MitRE, V., ARDELEAN, M., SESTRAS, R., SESTRAS, A. (2009.): Evaluation of old apple cultivars grown in central Transylvania, Romania. Not. Bot. Hort. Agrobot. Cluj 37 (1): 235-237.

SKENDROVIĆ BABOJELIĆ, M., KORENT, P., ŠINDRAK, Z., JEMRIĆ, T. (2014.): Pomološka svojstva i kakvoća ploda tradicionalnih sorata jabuka. Glasnik Zaštite Bilja, 37(3): 20-27.

SOSKA, A., TOMALA, K. (2006.): Internal quality of apples during storage. Agronomijas vēstis (Latvian Journal of Agronomy), 9; 146-151.

WURM, L., GÖSSINGER, M., WENDELIN, S., KIELER, M., RÜHMER, T., BRANDES, W., SIGL, K. (2015.): Yield, fruit quality, contents and sensory quality of old apple varieties trained as slender spindle under organic and integrated cultivation conditions. Geophysical Research Abstracts 17, EGU2015-1939. 


\author{
Adrese autora - Author's address: \\ Bernardica Milinović, e-mail: bernarda.milinovic@hcphs.hr \\ Predrag Vujević, \\ Dunja Halapija Kazija, \\ Tvrtko Jelačić, \\ Danijel Čiček, \\ Hrvatski centar za poljoprivredu hranu i selo \\ Zavod za voćarstvo, Gorice 68b, 10000 Zagreb
}

Ante Biško,

Agronomski fakultet Sveučilišta u Zagrebu,

Zavod za ishranu bilja,

Svetošimunska 25, 10000 Zagreb 